\title{
Prazo decadencial para benefícios previdenciários
}

Supremo Tribunal Federal (STF)

Recurso Extraordinário 626.489 - Sergipe

\section{Voto}

\section{O senhor ministro Luís Roberto Barroso (relator):}

EMENTA: DIREITO PREVIDENCIÁRIO. REGIME GERAL DE PREVIDÊNCIA SOCIAL (RGPS). REVISÃO DO ATO DE CONCESSÃO DE BENEFÍCIO. DECADÊNCIA.

1. O direito à previdência social constitui direito fundamental e, uma vez implementados os pressupostos de sua aquisição, não deve ser afetado pelo decurso do tempo. Como consequência, inexiste prazo decadencial para a concessão inicial do benefício previdenciário. 2. É legítima, todavia, a instituição de prazo decadencial de dez anos para a revisão de benefício já concedido, com fundamento no princípio da segurança jurídica, no interesse em evitar a eternização dos litígios e na busca de equilíbrio financeiro e atuarial para o sistema previdenciário. 3. O prazo decadencial de dez anos, instituído pela Medida Provisória 1.523, de 28.6.1997, tem como termo inicial o dia 1o de agosto de 1997, por força de disposição nela expressamente prevista. Tal regra incide, inclusive, sobre benefícios concedidos anteriormente, sem que isso importe em retroatividade vedada pela Constituição. 4 . Inexiste direito adquirido a regime jurídico não sujeito a decadência. 


\section{A hipótese}

1. O presente recurso extraordinário discute a incidência do prazo decadencial de dez anos - introduzido pela Medida Provisória no 1.523, de 28.6.1997 - sobre as pretensões de revisão de benefícios previdenciários instituídos antes dessa inovação legislativa. $\mathrm{O}$ caso concreto subjacente envolve aposentadoria por invalidez concedida a Maria das Dores Oliveira Martins, em 8.6.1995 (fl. 26). O Juizado Federal declarou extinta a demanda ajuizada pela aposentada, com resolução de mérito em seu desfavor. O fundamento foi a suposta decadência do direito à revisão, tendo em vista que a ação somente foi proposta em 3.6.2009, já após o referido prazo decenal. A Turma Recursal dos Juizados Especiais de Sergipe deu provimento ao recurso interposto da sentença e afastou a decadência, determinando ao juízo de origem que analisasse a questão de fundo. Dessa decisão foi interposto o recurso extraordinário. $\mathrm{O}$ provimento judicial impugnado tem a seguinte ementa:

DIREITO PREVIDENCIÁRIO. REVISÃO DE BENEFÍCIO PREVIDENCIÁRIO. DECADÊNCIA. NORMA DE DIREITO MATERIAL. APLICAÇÃO APENAS AOS BENEFÍCIOS PREVIDENCIÁRIOS CONCEDIDOS A PARTIR DA EDIÇÃO DE MEDIDA PROVISÓRIA № 1.523/1997. ENTENDIMENTO PACÍFICO DO SUPERIOR TRIBUNAL DE JUSTIÇA E DESTA TURMA RECURSAL. PRECEDENTES. PROVIMENTO DO RECURSO.

1. Esta Corte já firmou entendimento de que o prazo decadencial previsto no caput do artigo 103 da Lei de Benefícios, introduzido pela Medida Provisória no $1.523-9$, de 27.6.1997, convertida na Lei no 9.528/1997, por se tratar de instituto de direito material, surte efeitos apenas sobre as relações jurídicas constituídas a partir de sua entrada em vigor. Na hipótese dos autos, o benefício foi concedido antes da vigência da inovação mencionada e, portanto, não há que se falar em decadência do direito de revisão, mas, tão somente, da prescrição das parcelas anteriores ao quinquênio antecedente à propositura da ação (STJ, Agravo Regimental no Agravo de Instrumento n. 846.849/RS, Quinta Turma, Relator(a) JORGE MUSSI, DJE Data: 3/3/2008).

2. Como o benefício previdenciário revisando foi concedido à parte autora antes da vigência da Medida Provisória nํ1.523-9/1997 está imune à incidência do prazo decadencial. 
3. Orientação pacífica do Superior Tribunal de Justiça e desta Turma Recursal.

4. Provimento do recurso.

2. A controvérsia tem sua origem no fato de que a Lei no 8.213/1991, que dispõe sobre os Planos de Benefícios da Previdência Social, não continha previsão de prazo para a postulação de benefício previdenciário e tampouco para os pedidos de sua revisão. Previa-se apenas a incidência do prazo de cinco anos para a cobrança de parcelas vencidas e não pagas, preservando-se integralmente o fundo de direito. Confira-se a redação original do art. 103:

Art. 103. Sem prejuízo do direito ao benefício, prescreve em 5 (cinco) anos o direito às prestações não pagas nem reclamadas na época própria, resguardados os direitos dos menores dependentes, dos incapazes e dos ausentes. ${ }^{1}$

3. Posteriormente, a Medida Provisória no 1.523-9/1997 alterou a redação do dispositivo transcrito, passando a prever prazo decadencial para revisão do benefício inicialmente concedido, nos seguintes termos: ${ }^{2}$

Art. 103. É de dez anos o prazo de decadência de todo e qualquer direito ou ação do segurado ou beneficiário para a revisão do ato de concessão de benefício, a contar do dia primeiro do mês seguinte ao do recebimento da primeira prestação ou, quando for o caso, do dia em que tomar conhecimento da decisão indeferitória definitiva no âmbito administrativo.

4. A questão em debate, cuja repercussão geral foi reconhecida, consiste na aplicação ou não do prazo limitativo de dez anos para a revisão de benefícios previdenciários concedidos antes da MP no 1.523-9/1997. Existem,

1 Na Lei no 3.807/1960, anterior à Lei no 8.213/1991, o art. 57 possuía redação equivalente: "Não prescreverá o direito ao benefício, mas prescreverão as prestações respectivas não reclamadas no prazo de 5 (cinco) anos, a contar da data em que forem devidas".

2 A MP no 1.663-15/98, convertida na Lei no 9.711/1998, reduziu o prazo de dez para cinco anos, e a MP n⿳0 138/03, convertida na Lei nº 10.839/2004, voltou a estabelecer o prazo de dez anos, que é a redação atual. As modificações, todavia, não são relevantes para a solução da lide, pois não se completaram cinco anos desde o termo inicial instituído pela MP no 1.663-15/98 (1ㅇ.12.1998) e o início da vigência da MP nº 138/2003 (20.11.2003). 
em verdade, dois pontos a serem enfrentados: 1) a validade e o alcance da própria instituição de prazo para a revisão do ato concessório; e 2) a incidência imediata da alteração normativa a benefícios concedidos anteriormente à sua vigência.

5. As duas questões são analisadas a seguir.

\section{Validade e alcance da instituição de prazo para revisão do ato de concessão de benefício previdenciário}

6. O Regime Geral de Previdência Social (RGPS) constitui um sistema básico de proteção social, de caráter público, institucional e contributivo, que tem por finalidade segurar de forma limitada trabalhadores da iniciativa privada. A previdência social, em sua conformação básica, é um direito fundado na dignidade da pessoa humana, na solidariedade, na cidadania e nos valores sociais do trabalho (CF/88, art. 1ํㅡ, II, III e IV), bem como nos objetivos da República de construir uma sociedade livre, justa e solidária, avançar na erradicação da pobreza e na redução das desigualdades sociais (CF/88, art. 3o, I e III). ${ }^{3} \mathrm{i}$

7. Cabe distinguir, porém, entre o direito ao benefício previdenciário em si considerado - isto é, o denominado fundo do direito, que tem caráter fundamental - e a graduação pecuniária das prestações. Esse segundo aspecto é fortemente afetado por um amplo conjunto de circunstâncias sociais, econômicas e atuariais, variáveis em cada momento histórico. Desde a pirâmide etária e o nível de poupança privada praticado pelo conjunto de cidadãos até a conjuntura macroeconômica, com seu impacto sobre os níveis de emprego e renda.

8. Isso faz com que a definição concreta do sistema de previdência precise equacionar interesses por vezes conflitantes: dos trabalhadores ativos e dos segurados, dos contribuintes abastados e das pessoas mais humildes, da geração atual e das futuras. Em linha de princípio, a tarefa de realizar 3 i TAVARES, Marcelo Leonardo. Previdência e assistência social: legitimação e fundamentação
constitucional brasileira. Rio de Janeiro: Lumen Juris, 2003. p. 233-238. 
esse complexo equilíbrio situa-se na esfera de conformação do legislador, subordinando-se à decisão política das maiorias parlamentares. Somente haverá invalidade se a escolha legislativa desrespeitar o núcleo essencial do direito em questão. Resta saber se a instituição do prazo ora analisado e a sua incidência sobre os benefícios já concedidos incorreu ou não nesse tipo de vício.

9. Entendo que a resposta é negativa. No tocante ao direito à obtenção de benefício previdenciário, a disciplina legislativa não introduziu prazo algum. Vale dizer: o direito fundamental ao benefício previdenciário pode ser exercido a qualquer tempo, sem que se atribua qualquer consequência negativa à inércia do beneficiário. Esse ponto é reconhecido de forma expressa no art. 102, §1ํㅡㄹ da Lei $\mathrm{n}^{\mathrm{o}}$ 8.213/1991, ${ }^{4}$ bem como em diversas passagens em que a referida lei apenas dispõe que o atraso na apresentação do requerimento fará com que o benefício seja devido a contar do pedido, sem efeito retroativo. ${ }^{5}$ Nesse sentido, permanecem perfeitamente aplicáveis as Súmulas $443 / \mathrm{STF}^{6}$ e 85/STJ, ${ }^{7}$ na medida em que registram a imprescritibilidade do fundo de direito do benefício não requerido. ${ }^{8}$

10. A decadência instituída pela $M P \mathrm{n}^{\mathrm{o}}$ 1.523-9/1997 atinge apenas a pretensão de rever benefício previdenciário. Em outras palavras: a pretensão de discutir a graduação econômica do benefício já concedido. Como é natural, a instituição de um limite temporal máximo destina-se a resguardar a segurança jurídica, facilitando a previsão do custo global das prestações devidas. Em rigor, essa é uma exigência relacionada à manutenção do equilíbrio atuarial do sistema previdenciário, propósito que tem motivado

4 Lei $n^{\circ}$ 8.213/1991, art. 102, §1: “A perda da qualidade de segurado não prejudica o direito à aposentadoria para cuja concessão tenham sido preenchidos todos os requisitos, segundo a legislação em vigor à época em que estes requisitos foram atendidos". (Incluído pela Lei no 9.528, de 1997)

5 Por exemplo, art. 60, §1ํo (auxílio-doença), art. 49, I, “ $\mathrm{b}^{\prime}$ (aposentadoria por idade), art. 74, II, (pensão por morte), todos da Lei n⿳o 8.213/1991.

6 Súmula 443/STF: “a prescrição das prestações anteriores ao período previsto em lei não ocorre quando não tiver sido negado, antes daquele prazo, o próprio direito reclamado, ou a situação jurídica de que ele resulta".

7 Súmula 85/STJ: “Nas relações jurídicas de trato sucessivo em que a Fazenda Pública figure como devedora, quando não tiver sido negado o próprio direito reclamado, a prescrição atinge apenas as prestações vencidas antes do quinquênio anterior à propositura da ação".

8 Não se aplica em matéria previdenciária, entretanto, a conclusão das referidas súmulas quando há pedido administrativo indeferido. Nesse caso, somente perdem a exigibilidade as prestações atingidas pela prescrição, e não o próprio fundo de direito. 
sucessivas emendas constitucionais e medidas legislativas. Em última análise, é desse equilíbrio que depende a continuidade da própria Previdência, não apenas para a geração atual, mas também para as que se seguirão.

11. Com base nesse raciocínio, não verifico inconstitucionalidade na criação, por lei, de prazo de decadência razoável para o questionamento de benefícios já reconhecidos. Essa limitação incide sobre o aspecto patrimonial das prestações. Não há nada de revolucionário na medida em questão. É legítimo que o Estado-legislador, ao fazer a ponderação entre os valores da justiça e da segurança jurídica, procure impedir que situações geradoras de instabilidade social e litígios possam se eternizar. Especificamente na matéria aqui versada, não é desejável que o ato administrativo de concessão de um benefício previdenciário possa ficar indefinidamente sujeito à discussão, prejudicando a previsibilidade do sistema como um todo. Esse ponto justifica um comentário adicional.

12. O Regime Geral de Previdência Social é um sistema de seguro na modalidade de repartição simples, a significar que todas as despesas são diluídas entre os segurados. Não se trata, portanto, de um conjunto de contas puramente individuais, e sim de um sistema fortemente baseado na solidariedade. Isso aumenta a interdependência entre os envolvidos. Diante disso, há maior razão para a estipulação de um prazo razoável para a revisão de atos de concessão, conciliando os interesses individuais com o imperativo de manutenção do equilíbrio financeiro e atuarial do sistema.

13. Com essas considerações, entendo que inexiste violação ao direito fundamental à previdência social, tal como consagrado na Constituição de 1988. Não vislumbro, igualmente, qualquer ofensa à regra constitucional que exige a indicação prévia da fonte de custeio (art. 195, §5º) - irrelevante na hipótese - , e tampouco aos princípios da irredutibilidade do valor dos benefícios (art. 194, parágrafo único, IV) e da manutenção do seu valor real (art. 201, §4º). Tais comandos protegem a integridade dos benefícios já instituídos, e não um suposto direito permanente e incondicionado à revisão.

14. Assentada a validade da previsão de prazo, considero que o lapso de 10 (dez) anos é inequivocamente razoável. É tempo mais do que suficiente para a resolução de eventuais controvérsias interpretativas e para que o segurado busque as informações relevantes. É importante notar, nesse cenário, que a 
Lei no 8.213/1991 passou a prever o mesmo prazo para eventuais pretensões revisionais da Administração, nos termos do seu art. 103-A:

Art. 103-A. O direito da Previdência Social de anular os atos administrativos de que decorram efeitos favoráveis para os seus beneficiários decai em dez anos, contados da data em que foram praticados, salvo comprovada má-fé.

15. No encerramento deste tópico, é possível sintetizar os dois parâmetros gerais que devem reger a matéria:

a) não há prazo decadencial para a formulação do requerimento inicial de concessão de benefício previdenciário, que corresponde ao exercício de um direito fundamental relacionado à mínima segurança social do indivíduo;

b) a instituição de um prazo decadencial de dez anos para a revisão dos benefícios já concedidos é compatível com a Constituição Federal. Trata-se de uma conciliação razoável entre os interesses individuais envolvidos e os princípios da segurança jurídica e da solidariedade social, dos quais decorre a necessidade de se preservar o equilíbrio atuarial do sistema em benefício do conjunto de segurados atuais e futuros.

\section{A incidência imediata do novo prazo sobre benefícios previdenciários concedidos anteriormente a sua vigência}

16. O segundo ponto a ser equacionado na presente demanda envolve a aplicação intertemporal do art. 103 da Lei no 8.213/1991. Cuida-se de saber: a) se os benefícios previdenciários concedidos pelo INSS antes da instituição do prazo decadencial estariam alcançados pela norma; e b) em caso afirmativo, qual seria o termo inicial do prazo de decadência do direito à revisão desses benefícios.

17. O Supremo Tribunal Federal tem precedentes no sentido de que a lei aplicável para a concessão de benefício, bem como para fixar os critérios de seu cálculo, é a que estava em vigor no momento em que os pressupostos da prestação previdenciária se aperfeiçoaram, aplicando a máxima tempus regit actum. Com efeito, no julgamento do RE 415.454 (Rel. Min. Gilmar Mendes), o Plenário, por unanimidade, afirmou que a lei a ser aplicada ao cálculo da pensão por morte era a que estava em vigor no momento do óbito, não 
havendo direito subjetivo à prevalência de norma posterior mais favorável. Tampouco poderia ser utilizada para esse fim, como é natural, eventual lei superveniente mais gravosa.

18. Naquele julgamento, porém, estabeleceu-se uma clara distinção entre a necessidade de o ato concessivo ser regido pela lei vigente no momento de implementação dos requisitos de concessão e a possibilidade de alteração posterior do regime jurídico de disciplina da relação previdenciária, resguardados os direitos já adquiridos na pendência do regime anterior.

19. Esta é, precisamente, a questão que se coloca no presente recurso: não se incorpora ao patrimônio jurídico de um beneficiário o suposto direito à aplicação de uma determinada regra sobre decadência para eventuais pedidos de revisão do ato concessório. Como a decadência não integra o espectro de pressupostos e condições para a concessão do benefício - sendo um elemento externo à prestação previdenciária - , não se pode exigir a manutenção de seu regime jurídico.

20. No presente caso, a ausência de prazo decadencial para a revisão no momento em que o benefício foi deferido não garante ao beneficiário a manutenção do regime jurídico pretérito, que consagrava a prerrogativa de poder pleitear a revisão da decisão administrativa a qualquer tempo. Como regra, a lei pode criar novos prazos de decadência e de prescrição, ou ainda alterar os já existentes. Ressalvada a hipótese em que os prazos anteriores já tenham se aperfeiçoado, não há direito adquirido ao regime jurídico prévio. O limite, como visto, é a proteção ao núcleo do direito fundamental em questão, que não restou esvaziado como se demonstrou no tópico anterior.

21. O assunto não é novo e podem ser destacados pelo menos dois precedentes em que esta Corte aplicou raciocínio semelhante. $\mathrm{O}$ primeiro ocorreu quando do julgamento do RE 93698, em que a 1a Turma, sob a relatoria do Ministro Soares Muñoz, concluiu pela aplicação imediata de lei nova que reduzia prazo decadencial. No caso em que o lapso já decorrido seria superior ao novo prazo, decidiu-se pela desconsideração do primeiro e adoção imediata do segundo:

EMENTA: decadência. Direito intertemporal.

- Se o restante do prazo de decadência fixado na lei for superior ao novo prazo estabelecido pela lei nova, despreza-se o período já transcorrido 
para levar-se em conta, exclusivamente, o prazo da lei nova, a partir do início de sua vigência. Precedente: AR 905. Incidência da Súmula 286. Recurso não conhecido.

22. O segundo precedente foi firmado no julgamento do Recurso Extraordinário 564.354, sob a relatoria da Ministra Cármen Lúcia. No caso, o INSS sustentava a impossibilidade de aplicação dos novos limites previdenciários ("tetos") instituídos pela EC no 20/1998 e pela EC no 41/2004 aos benefícios anteriormente concedidos. Ao analisar a matéria, a Corte assentou que a nova disciplina devia ter aplicação imediata sobre os benefícios concedidos antes das referidas Emendas Constitucionais. Isso porque a mudança não atingia os pressupostos de concessão do benefício, e sim o regime jurídico de sua fruição. Destaco do voto da relatora:

Extrai-se daqueles julgados, citados à guisa de exemplo, afirmar este Supremo Tribunal não ser possível à lei posterior alcançar atos jurídicos efetivados antes de sua vigência, sob pena de ofensa ao princípio do ato jurídico perfeito.

Todavia, tem-se, na espécie em foco, situação distinta. A pretensão posta nesta lide respeita à aplicação imediata ou não do novo teto previdenciário trazido pela Emenda Constitucional n. 20/98, e não sua aplicação retroativa.

Assim, a meu ver, não há que se falar em ofensa ao ato jurídico perfeito (art. 5o, inc. XXXVI, da Constituição) ou ao princípio da irretroatividade da lei. ${ }^{9}$

23. O mesmo raciocínio deve prevalecer na análise da aplicação intertemporal de novo prazo decadencial. Esse elemento não compõe a estrutura dos pressupostos de um benefício, e sim o regime jurídico instituído para regulamentar a sua percepção corrente. Nesses termos, eventuais alterações posteriores devem ter incidência imediata, sem que se cogite de ofensa a

9 A afirmação de que a nova norma dispunha sobre aspecto exterior ao ato de concessão de benefício foi também desenvolvida no voto do Ministro Gilmar Mendes: "Esclarecida a origem meramente contábil da discrepância entre valor máximo do salário de contribuição e valor limitador previdenciário ('teto previdenciário'), a questão central do debate reside na elucidação da natureza jurídica do limitador previdenciário. Tenho que o limitador previdenciário, a partir de sua construção constitucional, é elemento externo à estrutura jurídica do benefício previdenciário, que não o integra". 
direito adquirido. Vale dizer: o fato de, ao tempo da concessão, não haver limite temporal para futuro pedido de revisão não significa que o segurado tenha um direito adquirido a que tal prazo nunca venha a ser estabelecido. O que se exige, ao revés, é a salvaguarda ao núcleo do direito e a instituição de um regime razoável, que não importe surpresa indevida ou supressão oportunista de pretensões legítimas.

24. Por fim, cabe analisar qual seria o termo inicial da contagem do prazo decadencial em relação aos benefícios concedidos antes da entrada em vigor da MP no 1.523-9/1997. Na redação que a medida provisória deu ao art. 103 da Lei no 8.213/1991, o prazo de dez anos tem o seu curso "a contar do dia primeiro do mês seguinte ao do recebimento da primeira prestação ou, quando for o caso, do dia em que tomar conhecimento da decisão indeferitória definitiva no âmbito administrativo". Ora bem: tendo em vista que a Medida Provisória foi publicada e entrou em vigor em 28.6.1997, a primeira prestação superveniente do benefício foi paga em julho de 1997. Nesse cenário, o termo inicial da prescrição é o dia 1o de agosto daquele mesmo ano.

25. Este foi, igualmente, o entendimento consagrado em decisão unânime proferida pela 1a Seção do Superior Tribunal de Justiça, no julgamento do REsp 1.303.988-PE, sob a relatoria do Ministro Teori Zavascki:

PREVIDÊNCIA SOCIAL. REVISÃO DO ATO DE CONCESSÃO DE BENEFÍCIO PREVIDENCIÁRIO. DECADÊNCIA. PRAZO. ART. 103 DA LEI 8.213/91. BENEFÍCIOS ANTERIORES. DIREITO INTERTEMPORAL.

1. Até o advento da MP 1.523-9/1997 (convertida na Lei 9.528/97), não havia previsão normativa de prazo de decadência do direito ou da ação de revisão do ato concessivo de benefício previdenciário. Todavia, com a nova redação, dada pela referida Medida Provisória, ao art. 103 da Lei 8.213/91 (Lei de Benefícios da Previdência Social), ficou estabelecido que "É de dez anos o prazo de decadência de todo e qualquer direito ou ação do segurado ou beneficiário para a revisão do ato de concessão de benefício, a contar do dia primeiro do mês seguinte ao do recebimento da primeira prestação ou, quando for o caso, do dia em que tomar conhecimento da decisão indeferitória definitiva no âmbito administrativo". 
2. Essa disposição normativa não pode ter eficácia retroativa para incidir sobre o tempo transcorrido antes de sua vigência. Assim, relativamente aos benefícios anteriormente concedidos, o termo inicial do prazo de decadência do direito ou da ação visando à sua revisão tem como termo inicial a data em que entrou em vigor a norma fixando o referido prazo decenal (28/06/1997). Precedentes da Corte Especial em situação análoga (v.g.: MS 9.112/DF Min. Eliana Calmon, DJ 14/11/2005; MS 9.115, Min. César Rocha (DJ de 7/8/06, MS 11123, Min. Gilson Dipp, DJ de 5/2/07, MS 9092, Min. Paulo Gallotti, DJ de 6/9/06, MS (AgRg) 9034, Min. Félix Ficher, DL 28/8/06).

3. Recurso especial provido. (Negrito acrescentado)

26. Merece especial destaque a seguinte passagem do voto do relator, na qual foi abordada, de forma expressa, a alegação de ofensa a direito adquirido:

Todavia, isso não significa que o legislador esteja impedido de modificar o sistema normativo em relação ao futuro, até porque, conforme de comum sabença, não há direito adquirido à manutenção de regime jurídico. É nessa perspectiva que, a exemplo do que fez a Corte Especial em relação ao artigo 54 da Lei 9.784, de 1999, deve ser interpretado e aplicado o art. 103 da Lei 8.213/91, com a redação que recebeu a partir da MP 1.523-9/97 e que resultou na conferida pela Lei 10.839/04. Com efeito, se antes da modificação normativa podia o segurado promover a qualquer tempo o pedido de revisão dos atos concessivos do benefício previdenciário, é certo afirmar que a norma superveniente não poderá incidir sobre o tempo passado, de modo a impedir a revisão; mas também é certo afirmar que a nova disposição legal está apta a incidir sobre o tempo futuro, a contar de sua vigência. Portanto, a solução para o problema de direito intertemporal aqui posto só pode ser aquela dada pela Corte Especial na situação análoga: relativamente aos benefícios previdenciários anteriores à nova lei, o prazo decadencial para sua revisão tem como termo inicial o da vigência da superveniente norma, que o estabeleceu. Esse modo de enfrentar a questão de direito intertemporal em situações da espécie é chancelado por abalizada doutrina. É o caso, por exemplo, de Galeno Lacerda, a propósito da redução do prazo decadencial da ação rescisória operada pelo CPC/73 (Novo Direito Processual Civil e os Feitos Pendentes, Forense, 1974, p. 100-101) e de Câmara Leal, em seu clássico Da Prescrição e da Decadência (Forense, 1978, p. 90). 
27. De fato, a lei nova que introduz prazo decadencial ou prescricional não tem, naturalmente, efeito retroativo. Em vez disso, deve ser aplicada de forma imediata, inclusive quanto às situações constituídas no passado. Nesse caso, o termo inicial do novo prazo há de ser o momento de vigência da nova lei ou outra data posterior nela fixada. O raciocínio é o mesmo estabelecido em precedentes do Supremo Tribunal Federal relativos à aplicação do art. 54 da Lei no 9.784/1999. ${ }^{10}$

28. No caso concreto em exame, o recurso extraordinário versa interesse de segurada que teve aposentadoria concedida anteriormente à entrada em vigor da $M P \mathrm{n}^{\mathrm{o}}$ 1.523-9/1997. A decisão recorrida deve ser reformada, na medida em que deixou de reconhecer a aplicabilidade do prazo decadencial de dez anos e assentou a possibilidade de revisão do ato de aposentadoria a qualquer tempo. Ao contrário do que entendeu a decisão recorrida, não há, na hipótese, direito adquirido protegido pelo art. 5o, XXXVI, da Constituição Federal.

29. Por essas razões, conheço do recurso extraordinário e lhe dou provimento, para reformar a decisão prolatada pela Turma Recursal dos Juizados Especiais de Sergipe. Como consequência, restabeleço a sentença proferida pelo Juizado Especial Federal de Sergipe no Processo 2009.85.00.502418-05, a qual havia declarado extinto o processo, com resolução de mérito, por força de decadência, nos termos do art. 269, IV, do Código de Processo Civil.

30. É como voto.

10 Lei no 9.784/1999, art. 54: “O direito da Administração de anular os atos administrativos de que decorram efeitos favoráveis para os destinatários decai em cinco anos, contados da data em que foram praticados, salvo comprovada má-fé". A decisão adotada pela 2a Turma do STF no julgamento do RMS 25856, Rel. Min. Eros Grau, fixou o entendimento de que "O prazo decadencial estabelecido no art. 54 da Lei 9.784/99 conta-se a partir da sua vigência (1º.2.1999), vedada a aplicação retroativa do preceito para limitar a liberdade da Administração Pública". E a 1ํ Turma da Corte dispôs no mesmo sentido, no julgamento do RMS (AgR) 27.022, Rel. Min. Ricardo Lewandowski, em que assentou que a aplicação imediata da lei que institui prazo para a Administração rever seus próprios atos não ofende direito adquirido, logo "o prazo de decadência deve ser computado a partir da vigência da lei que o instituiu e não tendo em conta atos pretéritos". 